\title{
Effects of harness-attached tracking devices on survival, migration, and reproduction in three species of migratory waterfowl
}

Thomas K. Lameris ${ }^{1,2^{*}}$, Gerhard J. D. M. Müskens ${ }^{3}$, Andrea Kölzsch ${ }^{1,4}$, Adriaan M. Dokter ${ }^{1,2}$, Henk P. Van der Jeugd ${ }^{1,5}$ and Bart A. Nolet ${ }^{1,2}$

\begin{abstract}
Background: Tracking devices have enabled researchers to study unique aspects of behavior in birds. However, it has become clear that attaching these devices to birds often affects their survival and behavior. While most studies only focus on negative effects on return rates, tracking devices can also affect the behavior under study, and it is therefore important to measure potential negative effects of tracking device attachment on the full range of behavioral aspects of birds. At the same time, we should aim to improve our current attachment methods to reduce these effects.

Results: We used a modified harness to attach tracking devices to a total of 111 individuals of three goose species (Greater White-fronted Geese, Brent Geese, and Barnacle Geese) to study their migratory behavior. By creating control groups of birds marked with colored leg bands, geolocators, and/or neck collars, we were able to compare return rates, body condition, and migratory and reproductive behavior, thus allowing a much broader comparison than return rates alone. Birds with harness-attached tracking devices had lower return rates, which could partly be explained by increased rates of divorce, but is likely also the result of reduced survival induced by the harness and device. A comparison between Barnacle Geese equipped with harness-attached tracking devices and individuals fitted with geolocators attached to leg bands showed that birds equipped with tracking devices were only slightly delayed in timing of migration and reproduction and otherwise were not affected in reproductive output.
\end{abstract}

Conclusions: We argue that tracking devices can be used for studies on migration timing. Nevertheless, given the effect of tracking devices on survival and divorce rate, which may differ between sexes and species, we stress that researchers should carefully consider which birds to tag in order to reduce potential negative effects.

Keywords: GPS tracking, Tag effects, Geolocators, Barnacle Goose, Brent Goose, Greater White-fronted Goose

\section{Background}

With the rise of advanced electronic tracking devices, such as satellite transmitters and GPS-loggers, scientists can now gather detailed data on movement of birds, allowing unique insights into their ecology and behavior $[23,36]$. However, attaching tracking devices potentially harms the survival of birds or affects their behavior [2], and the recorded data of tracking devices may thus be influenced by the tracking device itself. It is challenging

\footnotetext{
*Correspondence: thomaslameris@gmail.com

${ }^{1}$ Department of Animal Ecology, Netherlands Institute of Ecology (NIOOKNAW), Droevendaalsesteeg 10,6708 PB Wageningen, The Netherlands Full list of author information is available at the end of the article
}

to test for these potential negative effects. While negative effects of tracking devices remain ubiquitous in tracking studies, reporting rates of these effects have gone down over the past decades [26]. To ensure that tracking data reflects the natural behavior of birds, it is critical to apply rigorous tests for potential effects of tracking devices and to develop attachment methods that reduce the negative effects.

Modern solar-powered tracking devices collect data for multiple years, which requires an external and long-lasting attachment of the device to the bird. In such cases, harness attachment has been the method of choice for larger birds, including raptors $[24,38]$ and waterfowl [17, 
26]. Unfortunately, harnesses often have negative effects on birds, including reduced survival rates and reproductive success $[16,39]$, reduced migratory flight speed [20], and changes in behavior [17]. Although many studies report on negative effects of harness attachment on a single behavioral aspect, few studies have addressed multiple potential negative effects simultaneously (but see [19]), such that the full range of potential negative effects can be explored. Most notably, negative effects on migration are difficult to study, as tracking devices often are the main approach for measuring individual behavior during migration in the first place, and hence device effects on this behavior have hardly been studied [2]. However, it is important to study effects on multiple behavioral aspects, as negative effects can also carry over across parts of the annual cycle. For example, timing of migration can be strongly linked to timing of reproduction, and relatively small effects early in the season can thus ultimately affect the fitness of a bird.

Some of the negative effects of harness-attached tracking devices seem related to the harness attachment itself. Because migratory birds vary in body mass during the year [1], harnesses may become too tight or too loose, which can cause irritation to the bird [7] and abrasion of the skin [5]. The type of harness and its fitting to the individual bird can be pivotal in reducing the influence on the bird [7] and thus how representative the tracking data are for normal behavior [41].

We aimed to design a harness that can be easily tailored to individual birds, improving on an existing design. We examined the potential negative effects of this harness attachment for a set of behavioral aspects, including survival, migration, and reproduction, in order to gain a complete overview of the potential negative effects of this harness attachment. We used the harness to attach tracking devices to three Arctic-nesting migratory species of geese: greater white-fronted geese, Anser albifrons; Darkbellied brent geese, Branta bernicla bernicla; and barnacle geese, Branta leucopsis. We additionally created control groups of birds equipped with color bands and neck collars, including color bands with attached geolocators to record migration timing. Effect sizes between tagged birds and their control groups were compared for survival, for timing of migration and reproduction, and for reproductive output.

\section{Methods}

We modified an existing full-body harness design (e.g., [24]) with a neck and body loop (Fig. 1). Straps consisted of three materials (Teflon, Tygon, and nylon) to create a sturdy, but smooth, harness that was tubular in shape. We included sliding cramping rings, so we could quickly adjust the size of the neck and body loops when fitting the harness on different-sized birds and could easily fixate the loops by squeezing the rings with a pair of pliers. Stainless steel rings were used to connect the harness to the tracking device. Harnesses can be tailored to different-sized species or individuals by adjusting the length of the straps. Full methods and instructions on how to construct and deploy the harness can be found in Lameris et al. [27].

\section{Study species and capture methods}

From 2012 to 2014, we equipped in total 111 geese with tracking devices using this harness. Apart from a tracking device, all birds received metal and color bands for identification in the field. A larger sample of birds was equipped with only colored legbands or neck collars as control group.

During the winters of 2013/2014 and 2014/2015 in Noord Brabant, The Netherlands, 35 greater whitefronted geese ( 7 males, 7 females, 21 juveniles) were caught in family groups using a remote-controlled clap net (see [25]). Each bird was equipped with a plastic, numbered neck collar and a 45-g e-obs GPS-GSM transmitter with the described harness. Another 92 birds were captured and equipped only with neck collars.

On the islands Terschelling and Schiermonnikoog, The Netherlands in April and May 2012, brent geese were caught using canon nets. From these catches, 30 male geese (21 on Terschelling, 9 on Schiermonnikoog) were equipped with plastic, numbered colored legbands and 16-g UvA-BiTS GPS-loggers [3] attached with a prototype of the harness, while a control group was equipped with colored legbands only. The prototype differed from the latter type by lacking the outer layer of Teflon and having attachment rings made of carbon steel instead of stainless steel. In 2014, brent geese were caught using canon nets on Terschelling, and 6 female brent geese were equipped with 19-g UvA-BiTS GPS-loggers and the standard version of the harness (as described above: including an outer layer of Teflon and with attachment rings made of stainless steel). For our analysis on return rates, only geese caught on Terschelling were used as observation effort on Schiermonnikoog was too low.

At the Kolokolkova Bay, Russia, in June and July 2014, 40 adult female barnacle geese were caught on the nest during incubation using a remote-controlled clap net and equipped with plastic color legband and 19-g GPSloggers (UvA-BiTS, [3]) with the described harness. A control group of 40 adult female geese was either similarly caught on the nest (22 birds) or caught by rounding up flightless geese during molt (18 birds). The birds in the control group were equipped with two plastic color bands (6.6 g total) and an Intigeo C-65 Migrate Tech geolocator $(1 \mathrm{~g})$ attached to the left colored legband. 


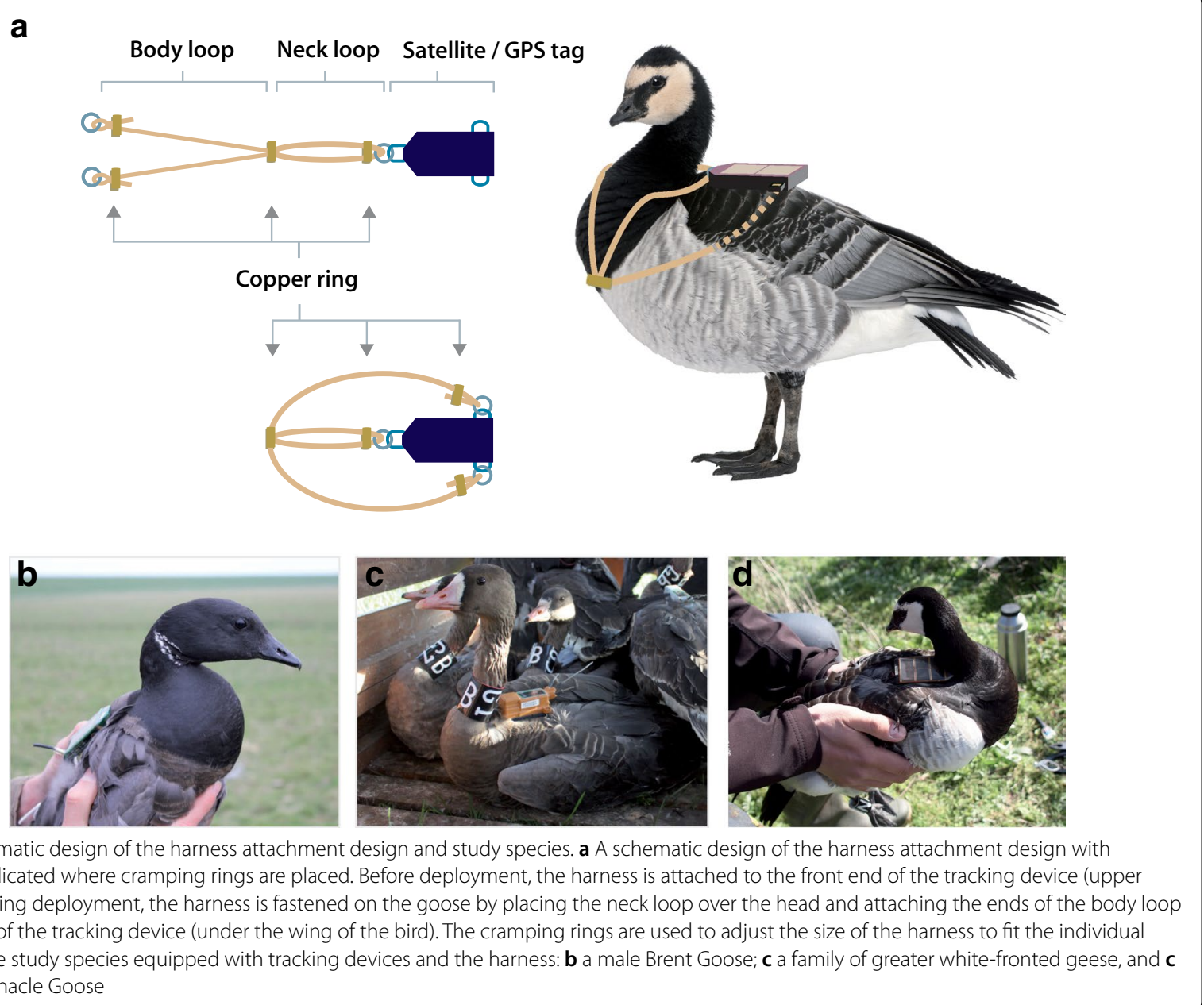

Because the geolocator weighed only a small fraction of the total weight of the two colored legbands, we assume that geese equipped with colored legbands and a geolocator would not differ in any behavior from geese with only colored legbands. As some of the geese in the control group were caught during catches during the molt period rather than on the nest, we ran analyses separate for the complete control group (40 geese) and the subset of geese caught on the nest (22 geese, in similar state as the geese with GPS-loggers).

\section{Comparison of parameters}

To calculate one-year return rates, we collected all resighting data from the focal birds from www.geese.org, an online platform where observers can submit sightings of individually marked geese and swans. Observations made by many volunteer band readers as well as those made by the researchers themselves were included. For barnacle geese, we calculated return rates based on birds caught during the molting period one year after equipping the birds with transmitters, as resightings of birds with GPS-loggers were biased, since we used GPS tracking data to find birds in the field.

We compared the timing of departure and migration speed of barnacle geese with harness attachments and those with geolocators as a control group. Data were retrieved at our study site in the Kolokolkova Bay, Russia, in the summer of 2015. Data from UvA-BiTS GPS-loggers were downloaded remotely using a Zigbee two-way receiver unit in the tracker connecting to a base station and six relays [3], after which these data were stored at the UvA-BiTS database. From this database, we downloaded the data as text files with latitude and longitude positions. The GPS-loggers had stored 48 to 288 accurate GPS locations (mean stationary error $=3.23 \mathrm{~m}$, [3]) per day. The Intigeo C-65 geolocators were retrieved from shot birds or by rounding up flightless birds during the molting period. After retrieving geolocators, data were downloaded and processed using the program Intiproc (Migrate technology 2014). Further analysis was 
carried out using the package 'GeoLight' [30] in R 3.0.2 [34]. The geolocators had recorded light intensity every $5 \mathrm{~min}$. Twilight events were identified using the 'threshold method' [11] at a light intensity value of 2 [31] and used to calculate two longitude positions per day (error of $140-400 \mathrm{~km}$, [31]). For both spring migration tracks acquired using GPS-loggers and geolocators, we determined the moment of departure from wintering site in the Wadden Sea area (first position with longitude $>9^{\circ}$ ) and the moment of departure from the Baltic Sea region (first position with longitude $>30^{\circ}$ ). For those geese that did not stop in the Baltic Sea region but migrated straight to the Arctic, the latter position was absent from geolocator data. For these geese, we took the day after the last day at which we could obtain a longitude position as the day of leaving the Baltic region. We calculated the speed of migration as the number of days between departure from the wintering grounds and departure from the Baltic region.

We measured reproductive performance of barnacle geese with harness attachments and those with geolocators at our study site at Kolokolkova Bay, Russia [37]. We searched for new nests and checked known nests every 2 to 3 days between 31 May and 25 June 2015. Eggs were marked, and the number of eggs was recorded at every visit. Nest initiation dates were determined as the day at which the first egg was laid. For incomplete clutches found during egg laying, initiation date was estimated as follows: 1 egg, day of discovery; 2 eggs, day of discovery minus 1; 3 eggs, day of discovery minus 3 , 4 eggs, day of discovery minus 4 [21]. Clutch size was only determined for nests with a stable number of eggs from the third visit onwards. We measured reproductive performance of brent geese with harness attachments by observing them on their wintering grounds in the Wadden Sea, the Netherlands, and by noting whether they were accompanied by juveniles.

In July and August 2015, we captured flightless barnacle geese using herders and boats. We visually assessed condition and damage on geese carrying harness attachments. We weighed geese using a spring scale $( \pm 10 \mathrm{~g})$.

\section{Statistical analyses}

All analyses were conducted using R 3.0.2 [34]. We compared one-year return rates of birds with the harness attachment and the control groups. We tested for significant differences between return rates using binomial logistic regression models that included species, sex, experimental group (harness or control), and the interaction effect of experimental group and species/sex. We used one-tailed Mann-Whitney U tests (as we expected only negative effects for birds with harness attachments) to compare differences in migratory behavior (departure date from the wintering grounds, departure date from the Baltic Sea region, migration speed) between birds with harness attachments and their control group. We used one-tailed Mann-Whitney U tests to compare the difference in reproductive parameters (nest initiation dates and clutch size) of barnacle geese equipped with harness attachments and their control group, where the control group consisted either of geese with geolocators or of birds without attached devices (i.e., only colored legbands). For some comparisons, sample sizes were low, and minor effects of harness attachments were probably not detectable. We provided $95 \%$ confidence intervals of effect sizes (Cohen's D) for all tests, rather than conducting a post hoc power analysis [11]. Also, we refrained from statistical tests on a number of parameters where detection probability was too low (including nesting propensity and divorce rate).

\section{Results \\ Return rates}

Geese with GPS-loggers or GPS-GSM transmitters experienced reduced one-year return rates compared to their control group (effect of harness attachment: $\beta=-1.14 \pm 0.28$ (SD); $z=-4.0 ; p<0.001$; odds ratio, 0.32 ; Table 1). This did not differ between species and sex/age groups, as the interaction effect between attachment and species or sex/age group was not present in the highest ranking models (Table 2).

\section{Migratory behavior}

We found no significant differences in the migratory behavior of barnacle geese with harness-attached GPSloggers and those with geolocators. However, the effect size suggests that birds with GPS-loggers were potentially slightly delayed ( 1 day) in moment of departure, including the moment of departure from the Wadden Sea region (GPS-logger, $N=18$ : $45 \pm 6$; geolocator, $N=18$ : $43 \pm 10$ days since 1 April; $W=136, d=0.43,95 \% \mathrm{CI}$ $[-0.26,1.11], p=0.21)$ and the moment of departure from the Baltic Sea region (GPS-logger, $N=18: 50 \pm 3$; geolocator, $N=19$ : $48 \pm 3$ days since 1 April; $W=138.5$, $d=0.47,95 \%$ CI $[-0.21,1.15], p=0.16)$. There was no difference in migration speed (GPS-logger, $N=18$ : $4.55 \pm 4.60$; geolocator, $N=18$ : $5.33 \pm 7.84$ days; $W=162$, $d=0.22,95 \%$ CI $[-0.46,0.90], p=0.51)$.

\section{Reproduction}

We found that 27 of 40 barnacle geese with harnessattached GPS-loggers returned to breed in 2015 and 20 initiated nests (17 nested successfully). Barnacle geese with geolocators also bred successfully, based on 12 found nests out of 40 tagged birds. Clutch sizes of geese with GPS-loggers did not differ between geese with 
Table 1 Return rates of birds equipped with harness-attached tracking devices (tagged birds) compared to their control groups, equipped with colored legbands or neck collars

\begin{tabular}{|c|c|c|c|c|c|c|c|}
\hline Species & Time frame of measurement & $\begin{array}{l}\text { Sample size } \\
\text { tagged birds }\end{array}$ & Return rate & $\begin{array}{l}\text { Sample } \\
\text { size control } \\
\text { group }\end{array}$ & Return rate & Coefficient & Odds ratio \\
\hline $\begin{array}{l}\text { Greater White-fronted Goose } \\
\text { (males) }\end{array}$ & $\begin{array}{l}\text { Winter 2013/2014-winter } \\
\text { 2014/2015 and win- } \\
\text { ter 2014/2015-winter } \\
\text { 2015/2016 }\end{array}$ & 7 & 0.43 & 13 & 0.62 & -0.37 & 0.69 \\
\hline $\begin{array}{l}\text { Greater White-fronted Goose } \\
\text { (females) }\end{array}$ & $\begin{array}{l}\text { Winter 2013/2014-winter } \\
\text { 2014/2015 and win- } \\
\text { ter 2014/2015-winter } \\
\text { 2015/2016 }\end{array}$ & 7 & 0.29 & 13 & 0.69 & -1.34 & 0.26 \\
\hline $\begin{array}{l}\text { Greater White-fronted Goose } \\
\text { (juveniles) }\end{array}$ & $\begin{array}{l}\text { Winter 2013/2014-winter } \\
\text { 2014/2015 and win- } \\
\text { ter 2014/2015-winter } \\
\text { 2015/2016 }\end{array}$ & 21 & 0.29 & 66 & 0.70 & -1.37 & 0.25 \\
\hline Brent goose (males) & May 2012-May 2013 & 21 & 0.52 & 37 & 0.78 & -0.81 & 0.44 \\
\hline Brent goose (females) & May 2014-May 2015 & 6 & 0.83 & 15 & 0.93 & -0.65 & 0.52 \\
\hline \multirow[t]{2}{*}{ Barnacle goose (females) } & June 2014-August 2015 & 40 & 0.45 & 40 & 0.55 & -0.40 & 0.67 \\
\hline & & & & $22^{\mathrm{a}}$ & 0.55 & -0.38 & 0.68 \\
\hline
\end{tabular}

For each return rate, we give the time frame of the measurement over which the return rate has been measured, the coefficient value taken from logistic regression models (representing the change in log odds) and the odds ratio

a For this comparison, only the subset of control birds caught on the nest is used as a control group

Table 2 Final binomial logistic regression models for return rates over species (S), sex/age groups (A), attachment treatment $(T)$, the interaction between treatment and species $(T \times S)$, and the interaction between treatment and sex/ age groups $(T \times A)$

\begin{tabular}{|c|c|c|c|c|c|c|c|c|}
\hline Return rate & Intercept & Species (S) & Sex/age (A) & Treatment $(\mathrm{T})$ & $\begin{array}{l}\text { Treatment } \times \text { Species } \\
(T \times S)\end{array}$ & $\begin{array}{l}\text { Treatment } \times \text { Sex } / \\
\text { Age }(T \times A)\end{array}$ & $\begin{array}{l}\text { Degrees } \\
\text { of freedom }\end{array}$ & $\Delta \mathrm{AICC}$ \\
\hline$\sim S+T$ & 0.673 & $0.88^{*}$ & & $-1.14^{* * *}$ & & & 4 & 0.00 \\
\hline$\sim T$ & 0.900 & & & $-1.14^{* * *}$ & & & 2 & 0.28 \\
\hline$\sim S+T+T^{*} S$ & 0.182 & $1.38^{*}$ & & -0.38 & -1.17 & & 6 & 12.13 \\
\hline$\sim S$ & -0.065 & $1.15^{* *}$ & & & & & 3 & 12.15 \\
\hline$\sim \mathrm{S}+\mathrm{A}+\mathrm{T}$ & 0.669 & $1.36^{*}$ & -0.64 & $-1.13^{* * *}$ & & & 6 & 13.12 \\
\hline$\sim S+T+S^{*} A$ & 0.395 & $1.47^{* *}$ & & -0.71 & & -1.04 & 8 & 46.11 \\
\hline
\end{tabular}

Coefficient values are given, with asterisks denoting significant effects $\left({ }^{*} p<0.05 ;{ }^{* *} p<0.01 ;{ }^{* * *} p<0.001\right)$

geolocators and other birds in the colony (GPS-logger: $4.3 \pm 1.0$ eggs, $N=18$; geolocator: $4.5 \pm 0.93$ eggs, $N=11$; colony: $4.4 \pm 1.2$ eggs; $N=351$; GPS-logger vs geolocator: $W=80, d=0.51,95 \%$ CI $[-0.28,1.31], p=0.19$; GPSlogger vs colony: $W=3307, d=0.51,95 \%$ CI $[-0.36$, 0.59 ], $p=0.64$ ). However, geese with GPS-loggers initiated egg laying on average 2-3 days later than geese with geolocators and other geese in the colony (GPSloggers: $37.1 \pm 1.9$ days since 1 May, $N=18$; geolocator: $34.1 \pm 2.0$ days since 1 May, $N=8$; colony: $34.7 \pm 2.4$ days since May 1st, $N=216$; GPS-logger vs geolocator: $W=106.5, d=1.35,95 \%$ CI $[0.39,2.31], p=0.004$; GPSlogger vs colony: $W=917.5, d=0.67,95 \%$ CI $[0.18,1.16]$, $p<0.001)$.
Of the female brent geese equipped with harnessattached GPS-loggers, three of five females that returned to the wintering grounds in 2014 nested successfully, as they were accompanied by juveniles. Tagged males did not nest successfully in 2013, but it must be noted that nesting success was generally very low this year, also for untagged geese.

\section{Other effects}

Twelve out of the 18 barnacle geese with harnessattached GPS-loggers which we recaptured during molt were either not damaged, or only missing some down feathers in the axillar region or had some broken back feathers below the logger. Four geese were missing 
feathers in the axillar region and had broken back feathers, and two birds had suffered from more severe damage, showing old wounds in the axillar region. Body mass during molt did not differ between birds with GPS-loggers, geolocators, or only colored legbands (GPS-logger: $1621 \pm 120$ g, $N=18$; geolocator: $1645 \pm 103$ g, $N=22$; colored legbands: $1620 \pm 137$ g; $N=3186$; GPS-logger vs geolocator: $W=237, d=0.34,95 \%$ CI $[-0.31,0.99]$, $p=0.29$; GPS-logger vs colony: $W=1720, d=0.05,95 \%$ CI $[-0.44,0.53], p=0.85)$. The harnesses themselves were only slightly damaged and showed some wear of Teflon at the outer loops.

Although all 14 observed male brent geese with harness-attached tracking devices had a mate after the initial catch in 2012, only $36 \%$ of those males returned with their original partner in 2013 (but at least two males were able to find a new partner during that spring period). Of the six females with harness-attached tracking devices in 2014, all returned with their original partner.

Of seven families of White-fronted Geese equipped with harness-attached tracking devices, the parents of two families separated within a week after tag attachment. Only one of the six tagged juveniles in those two families was not shot or predated during spring migration. Even if juvenile survival was higher for the five other families, none of the parents of those families returned to the wintering grounds together in the following year.

\section{Discussion}

We show that harness-attached tracking devices can have negative effects on return rates and can affect behavior, but effects can differ considerably between species and sexes. Reduced return rates of geese with harness attachment compared to a control group can be partly explained by birds not returning to their original wintering or breeding grounds, but we argue that this is largely the result of a reduced survival. More specifically, we show that tracking devices can affect multiple aspects of behavior, including a potential increase in divorce probability, but only slightly affect timing of migration and reproduction.

Return rates can be used as an index for survival, if individuals have high site fidelity and a high probability of being observed if alive. Individual brent geese return to the island of Terschelling every spring, and due to the open landscape and high observation effort, individuals have close to a $100 \%$ chance of being observed when alive. The same holds for greater white-fronted geese, due to the good visibility of the neck collars combined with a large network of voluntary ring-readers in the Netherlands. We observed female barnacle geese at their breeding colony, to which female geese are known to return every year [22], and we maximized our observation and recapture effort in an attempt to detect all individuals present. Non-observed individuals were never detected in subsequent years, supporting the conclusion that detection rate was high and non-observed individuals were likely to be dead. Lower return rates should thus indeed represent lower survival rates.

However, male geese tend to follow the female yearround and can thus change wintering area when divorcing from their original partner. Divorce rates are extremely low for geese (average of 3\% per year for several species of geese) because they benefit from long-lasting partnerships [12]. Our results suggest that divorce rates for male brent geese and greater white-fronted geese with harness-attached tracking devices were relatively high, and increased divorce rates have also been reported for female brent geese with transmitters [39] or neck collars [29]. The attachment of a tracking device might affect the quality of the bird as a partner, as found for brent geese $[8,18]$, and this may drive divorces between birds. Divorces may subsequently decrease reproductive output and survival [28]. The decreased return rates of male brent geese could also be affected by individuals switching to different wintering sites, as divorced birds would follow their new partners to other wintering sites. Negative effects related to divorces are therefore likely to be sex-specific, as we find high divorce rates for male brent geese but not for female Brent or barnacle geese. These effects of tracking device attachment could potentially be avoided when tagging females rather than males, and the choice of which birds are being tagged can thus importantly influence the success of a tracking study. In addition, the low return rates of male brent geese might be explained by the use of a prototype of the harness, with carbon steel rings potentially more prone to breaking after prolonged exposure to marine (salt) environments, causing (partial) harness detachment. The harnesses used later in this study were made stronger by using stainless steel rings and an outer layer of Teflon.

Besides potential shifts in wintering grounds for divorced male geese, decreased return rates of individuals equipped with harness-attached tracking devices likely indicate a lower survival of these birds. Some studies have found that harnesses negatively affect return rates and survival in geese [10,16,39], but other studies did not find such negative effects $[14,15]$. These latter studies measured return rates over a shorter time span. Attachment of tracking devices may increase the susceptibility of birds to being predated or shot, as shown by causes of death from tagged greater white-fronted geese in this study, of which out of 35 birds, 14 had been retrieved as shot, and 7 as predated by large birds of prey or fox during the spring migration following tag deployment. This may be caused by a change in behavior (e.g., increased 
time spent preening, [13]) or reduced flight maneuverability by the cross-sectional profile of the backpack tag causing additional drag [4], and perhaps not so much hunters targeting for marked geese [6]. Although our study found negative effects on return rates, our survival rates of tagged individuals were definitively higher than in some other studies [39],

Harness attachments may have negative effects on survival, but are also likely to have non-lethal effects on migratory birds [26]. By using a control group from which we have individual data on migration timing gained from geolocators, we can show convincingly that harness attachments cause only a slight delay in timing of migration departure for barnacle geese. This effect was not significant, and there exists a high degree of variation between individuals. Also, the migration speed of these birds was not affected. For comparison, an earlier study in northern pintails Anas acuta found that birds with harness-attached tracking devices arrived 19 days later on the breeding grounds in comparison with the population mean [20]. This is ascribed to a higher cost of migration, which is also suggested by models from Pennycuick et al. [32]. Also, we found a 2-3-day delay in laying date for barnacle geese with harness attachments, which is minor in comparison with earlier studies on mallards Anas platyrhynchos with harness attachments, which were delayed between 8 and 14 days [33,35]. We did not find effects on clutch size or on nest success, while these aspects of reproduction are susceptible to negative effects of harnesses attachment [16, 33, 35]. Although we were not able to measure differences in body stores of birds on arrival, any potential differences had disappeared after the nesting period, because we did not find a difference in body mass of female barnacle geese with harness attachment and females in control groups.

Our results are concurrent with recent reviews on the negative effects of tracking devices on birds [2, 26, 40]. We show that harness-attached transmitters can negatively affect survival but also pair-bonding, and thus the potential of birds to initiate breeding. These negative effects can have important consequences for behavior measured by tracking devices. While we find a delay in timing of reproduction and possibly timing of migration for birds with harness-attached transmitters, the delay is only minor, and other aspects of migration or reproduction are not affected. In contrast with earlier studies, which have shown strong negative effects on migration timing and reproduction for birds equipped with tracking devices [20,33, 35], we find that tracking devices are reliable tools to study timing of migration and reproduction, and the modified harness which we have developed appears to be a reliable method to attach tracking devices on geese. Given our different results for different sexes, we stress that researchers make a careful consideration which birds they equip with tracking devices.

\section{Authors' contributions}

TL, AK, AD, HvdJ, and BN conceptualized the study; TL, GM, AK, AD, and HvdJ collected the data; TL, AK, and AD analyzed the data; TL wrote the manuscript; and AK, AD, HvdJ, and BN revised the manuscript. All authors read and approved the final manuscript.

\section{Author details}

${ }^{1}$ Department of Animal Ecology, Netherlands Institute of Ecology (NIOOKNAW), Droevendaalsesteeg 10,6708 PB Wageningen, The Netherlands. ${ }^{2}$ Theoretical and Computational Ecology, Department of Science, Institute for Biodiversity and Ecosystem Dynamics, University of Amsterdam, PO Box 94248, 1090 GE Amsterdam, The Netherlands. ${ }^{3}$ Wageningen Environmental Research (Alterra), Droevendaalsesteeg 3, 6708 PB Wageningen, The Netherlands. ${ }^{4}$ Department of Migration and Immuno-Ecology, Max Planck Institute for Ornithology, Radolfzell, Germany. ${ }^{5}$ Centre for Avian Migration and Demography, Netherlands Institute of Ecology (NIOO-KNAW), Droevendaalsesteeg 10, 6700 AB Wageningen, The Netherlands.

\section{Acknowledgements}

We thank the Dutch Association of Goose catchers for catching greater white-fronted geese, Femke Jochems, Aljona Lemazina, and Stefan Sand for the help in catching barnacle geese, and Kees Oosterbeek and a large team of volunteers for the help in catching brent geese. We thank Staatsbosbeheer Terschelling and Natuurmonumenten Schiermonnikoog for permitting catching on their grounds. We thank Rob van Bemmelen for the help in analyzing geolocation data, Monique Beijaert for the help in designing Fig. 1, and Paul Flint, Gary Ritchison, and three anonymous reviewers for the help in improving the manuscript.

\section{Competing interests}

The authors declare that they have no competing interests.

\section{Availability of data and materials}

The datasets used and/or analyzed during the current study are available from the corresponding author on reasonable request.

\section{Consent for publication}

Not applicable.

\section{Ethics approval and consent to participate}

All field data were collected in compliance with national guidelines regarding animal welfare and were approved by the animal experimentation committee of the Royal Netherlands Academy of Arts and Sciences (DEC-KNAW), under protocols NIOO 12.04, NIOO 13.14, and NIOO 14.07.

\section{Funding}

TL was funded by the Nederlandse Organisatie voor Wetenschappelijk Onderzoek, grant NPP 866.13.010.

\section{Publisher's Note}

Springer Nature remains neutral with regard to jurisdictional claims in published maps and institutional affiliations.

Received: 8 September 2017 Accepted: 12 May 2018

Published online: 08 June 2018

\section{References}

1. Ankney CD. Annual cycle of body weight in Lesser Snow Geese. Wildl Soc Bull. 1982;10:60-4.

2. Barron DG, Brawn JD, Weatherhead PJ. Meta-analysis of transmitter effects on avian behaviour and ecology. Methods Ecol Evol. 2010;1:180-7.

3. Bouten W, Baaij EW, Shamoun-Baranes J, Camphyusen KCJ. A flexible GPS tracking system for studying bird behaviour at multiple scales. J Ornithol. 2012:154:571-80. 
4. Bowlin MS, Henningsson P, Muijres FT, Vleugels RH, Liechti F, Hedentström A. The effects of geolocator drag and weight on the flight ranges of small migrants. Methods Ecol Evol. 2010;1:398-402.

5. Capelle J, Iverson SA, Takekawa JY, Newman SH, Dodman T, Gaidet N. Implementing telemetry on new species in remote areas: recommendations from a large-scale satellite tracking study of African waterfowl. Ostrich. 2011:82:17-26.

6. Caswell JH, Alisauskas RT, Leafloor JO. Effect of neckband color on survival and recovery rates of Ross's geese. J Wildl Manag. 2012:76:1456-61.

7. Chan Y-C, Brugge M, Tibbitts TL, Dekinga A, Porter R, Klaassen RHG, Piersma T. Testing an attachment method for solar- powered tracking devices on a long-distance migrating shorebird. J Ornithol. 2016:157:277-87.

8. Clausen $\mathrm{P}$, Green M, Alerstam T. Energy limitations for spring migration and breeding: the case of brent tracked geese Branta bernicla tracked by satellite telemetry to Svalbard and Greenland. Oikos. 2003;103:426-45.

9. Colegrave N, Ruxton GD. Confidence intervals are a more useful complement to nonsignificant tests than are power calculations. Behav Ecol. 2003;14(3):446-7.

10. Dzus EH, Clark RG. Effects of harness-style and abdominally implanted transmitters on survival and return rates of Mallards. J Field Ornithol. 1996;67:549-57.

11. Ekstrom PA. An advance in geolocation by light. In: Naito Y, editor. Memoirs of the national institute of polar research, Special issue. Tokyo: National Institute of Polar Research; 2004. p. 210-26.

12. Ens BJ, Choudhury S, Black JM (1996) Mate fidelity and divorce in monogamous birds. Partnerships in Birds: 1996: 345-401.

13. Enstipp MR, Frost J, Hollmén TE, Andrews RD, Frost C. Two methods of radio transmitter attachment and their effects on the behavior and energetics of captive long-tailed ducks (Clangula hyemalis) during winter. Anim Biotelemetry. 2015;3(1):36.

14. Fleskes JP. Effects of backpack radiotags on female northern pintails wintering in California. Wildl Soc Bull. 2003;31:212-9.

15. Fox $A D$, Gladher $C M$, Walsh AJ. Spring migration routes and timing of Greenland white-fronted geese - results from satellite telemetry. Oikos. 2003;103:415-25.

16. Garrettson PR, Rohwer FC. Reproductive effort and survival of wild Bluewinged Teal, Anas discors, with backpack harness and implant transmitters. Can Field Nat. 1998;112:212-6.

17. Gladher C, Fox AD, Walsh A. Effects of fitting dummy satellite transmitters to Greenland White-fronted Geese Anser albifrons flavirostris. Wildfowl. 1997:48:88-97.

18. Green M, Alerstam T, Clausen P, Drent RH, Ebbinge BS. Dark-bellied Brent Geese Branta bernicla bernicla, as recorded by satellite telemetry, do not minimize flight distance during spring migration. Ibis. 2002;144:106-21.

19. Hupp JW, Pearce JM, Mulcahy DM, Miller DA. Effects of abdominally implanted radiotransmitters with percutaneous antennas on migration, reproduction, and survival of Canada geese. J Wildl Manag. 2006;70(3):812-22.

20. Hupp JW, Kharitonov S, Yamaguchi NM, Ozaki K, Flint PL, Pearce JM, et al. Evidence that dorsally mounted satellite transmitters affect migration chronology of Northern Pintails. J Ornithol. 2015;156:977-89.

21. van der Jeugd HP, Eichhorn G, Litvin KE, Stahl J, Larsson K, van der Graaf $\mathrm{AJ}$, Drent RH. Keeping up with early springs: rapid range expansion in an avian herbivore incurs a mismatch between reproductive timing and food supply. Glob Change Biol. 2009;15:1057-71.

22. Karagicheva J, Rakhimbardiev E, Dobrynin D, Saveliev A, Rozenfeld S, Pokrovskaya $\mathrm{O}$, et al. Individual inter-annual nest-site relocation behaviour drives dynamics of a recently established Barnacle Goose Branta leucopsis colony in sub-arctic Russia. Ibis. 2011;153(3):622-6.
23. Kays R, Crofoot MC, Jetz W, Wikelski M. Terrestrial animal tracking as an eye on life and planet. Science 2015;348: aaa2478.

24. Klaassen RHG, Strandberg R, Hake M, Alerstam T. Flexibility in daily travel routines causes regional variation in bird migration speed. Behav Ecol Sociobiol. 2008:62:1427-32.

25. Kölzsch A, Müskens GJDM, Kruckenberg H, Glazov P, Weinzierl R, Nolet BA, Wikelski M. Towards a new understanding of migration timing: slower spring than autumn migration in geese reflects different decision rules for stopover use and departure. Oikos. 2016;125:1496-507.

26. Lameris TK, Kleyheeg E. Reduction in adverse effects of tracking devices on waterfowl requires better measuring and reporting. Anim Biotelemetry. 2017;5:24.

27. Lameris TK, Kölzsch A, Dokter A, Nolet BA, Müskens GJDM. A novel harness for attaching tracking devices to migratory geese. Goose Bull. 2017;22:35-40.

28. Leach AG, Sedinger JS. Male breeding experience, not mate familiarity, affects reproductive output in black brant geese. Behav Ecol. 2016;27(6):1851-8.

29. Lensink CJ. Neckbands as an inhibitor of reproduction in Black Brant. J Wildl Manag. 1968:32:418-20.

30. Lisovski S, Hahn S. GeoLight - processing and analysing light-based geolocator data in R. Methods Ecol Evol. 2012;3(6):1055-9.

31. Lisovski S, Hewson CM, Klaassen RHG, Korner-Nievergelt F, Kristensen MW, Hahn S. Geolocation by light: accuracy and precision affected by environmental factors. Methods Ecol Evol. 2012;3:603-12.

32. Pennycuick CJ, Fast PL, Ballerstädt N, Rattenborg N. The effect of an external transmitter on the drag coefficient of a bird's body, and hence on migration range, and energy reserves after migration. J Ornithol. 2012;153(3):633-44.

33. Pietz PJ, Krapu GL, Greenwood RJ, Lokemoen JT (1993) Effects of harness transmitters on behavior and reproduction of wild Mallards. Journal of Wildlife Management 1993;696-703.

34. R Development Core Team. R: a language and environment for statistical computing; 2014

35. Rotella JJ, Howerter DW, Sankowski TP, Devries JH. Nesting effort by wild Mallards with 3 types of radio-transmitters. J Wildl Manag. 1993;57(4):690-5.

36. Seegar WS, Cutchis PN, Fuller MR, Suter JJ, Bhatnagar V, Wall JG. Fifteen years of satellite tracking development and application to wildlife research and conservation. Johns Hopkins Apl Tech Digest. 1996;17:401-11.

37. van der Jeugd HP, Gurtovaya E, Eichhorn G, Litvin KY, Mineev OY, van Eerden M. Breeding barnacle geese in Kolokolkova Bay, Russia: number of breeding pairs, reproductive success and morphology. Polar Biol. 2003;26(11):700-6

38. Vansteelant WMG, Bouten W, Klaassen RHG, Koks BJ, Schlaich AE, van Diermen J, et al. Regional and seasonal flight speeds of soaring migrants and the role of weather conditions at hourly and daily scales. J Avian Biol. 2015:46:25-39.

39. Ward D, Flint P. Effects of harness-attached transmitters on premigration and reproduction of Brant. J Wild Manag. 1995:59:39-46.

40. White CR, Cassey P, Schimpf NG, Halsley LG, Green JA, Portugal SJ. Implantation reduces the negative effects of bio-logging devices on birds. J Exp Biol. 2013;216(4):537-42.

41. Wilson RP, McMahon CR. Measuring devices on wild animals: what constitutes acceptable practice? Front Ecol Environ. 2006;4:147-54. 